\title{
Regulation of Extraadrenal Steroid
}

\section{1-Hydroxylase Activity}

\author{
INCREASED CONVERSION OF PLASMA PROGESTERONE TO \\ DEOXYCORTICOSTERONE DURING ESTROGEN TREATMENT OF WOMEN
}

\author{
PREGNANT WITH A DEAD FETUS \\ Paul C. MacDonald, Susan Cutrer, Sue C. MacDonald, M. LinetTe Casey, \\ and C. Richard Parker, Jr., Cecil H. and Ida Green Center for Reproductive \\ Biology Sciences, Departments of Obstetrics-Gynecology and Biochemistry, \\ The University of Texas, Southwestern Medical School, Dallas, Texas 75235
}

A BSTRACT We measured deoxycorticosterone (DOC) and progesterone $(\mathrm{P})$ in plasma of 47 women pregnant with a dead fetus and sequentially throughout gestation in 35 women pregnant with a live fetus. When P levels in plasma were low, the plasma levels of DOC in women pregnant with a dead fetus varied but usually were similar to those in women pregnant with a live fetus. However, when $\mathrm{P}$ levels were high, the levels of DOC in some women pregnant with a dead fetus were considerably lower than those in women pregnant with a live fetus. To test whether this finding was due to loss of transfer of DOC from fetus to mother or else loss of extraadrenal steroid 21-hydroxylase activity in the mother after death of the fetus, we conducted several studies. The levels of $P$ and DOC in plasma of one woman remained constant from $30 \mathrm{~min}$ after fetal death until delivery occurred $13 \mathrm{~h}$ later. Estrogen treatment of four women pregnant with a dead fetus brought about an increase in plasma levels of DOC in three of the women. In one woman the ratio of plasma DOC to $P$ was 0.015 , a value similar to that found before fetal death, but was 0.003 after fetal death but before estrogen treatment. In two women pregnant with a dead fetus the transfer constants of conversion of plasma $P$ to DOC were 0.011 and 0.005 before, and 0.024 and 0.013 , respectively, during estrogen treatment. In one woman pregnant with a deformed fetus with adrenal agenesis, the metabolic clearance rates of DOC before and during estrogen treatment were similar, whereas the plasma production rates of DOC were 2.75 before and 4.31 $\mathrm{mg} / 24 \mathrm{~h}$ during estrogen treatment. We suggest that (a) the DOC in plasma of near-term pregnant women arises in part by extraadrenal 21-hydroxylation of

Received for publication 17 July 1981 and in revised form 25 September 1981. plasma $P$ and (b) estrogen stimulates steroid 21-hydroxylase activity in extraadrenal tissues.

\section{INTRODUCTION}

Deoxycorticosterone (DOC) ${ }^{1}$ and $\mathrm{DOC}^{-\mathrm{SO}_{4}}$ levels in plasma of pregnant women are extraordinarily high compared with those found in men and nonpregnant women (1-8). Importantly, most of the DOC in plasma of near-term pregnant women arises by a mechanism(s) other than adrenal secretion. This obtains because dexamethasone treatment of near-term pregnant women does not cause a decrease in DOC levels in plasma $(1,3,4,6)$, and ACTH treatment of such women does not cause an increase in the plasma concentrations of DOC $(3,4,6)$.

It has been suggested that DOC produced in the fetus may be transferred to the mother because the levels of DOC and DOC-SO ${ }_{4}$ in umbilical cord plasma $(1,5,8-10)$ are even greater than those in maternal plasma. Alternatively, we recently suggested that DOC in the maternal compartment arises, in part, by the extraadrenal 21-hydroxylation of plasma progesterone (P) (11). Plasma P is converted to DOC, but the transfer constant of conversion of plasma $P$ to DOC $\left([\rho]_{B U}^{p-D O C}\right)$ varies widely among normal persons (11). Interestingly, the kidney of the human adult and fetus may be one site of extraadrenal synthesis of DOC because steroid 21-hydroxylase activity has been demonstrated in human adult (12) and fetal (13) kidney tissue.

\footnotetext{
${ }^{1}$ Abbreviations used in this paper: DOC, deoxycorticosterone; $\mathrm{DOC}_{-} \mathrm{SO}_{4}$, deoxycorticosterone sulfate; $\mathrm{P}$, progesterone; $[\rho]_{\mathrm{BU}}^{\mathrm{P}-\mathrm{DOC}}$, transfer constant of conversion of plasma progesterone to DOC; MCR, metabolic clearance rate; PR, production rate; tetrahydro-DOC, 3 $\alpha, 21$-dihydroxy-5 $\beta$-pregnan-20-one; TLC, thin-layer chromatography; tetrahydro-DOC-diacetate, $5 \beta$ pregnan-20-one-3 $\alpha, 21$-diacetate.
} 
In our investigation we sought initially to evaluate directly the fetal contribution of DOC to the maternal compartment. We did so by measuring DOC and $\mathrm{P}$ in plasma of women pregnant with a dead fetus. We found that in such women the plasma levels of DOC were quite variable but in most instances were similar to those in women pregnant with a live fetus when $P$ levels in plasma of the women of the two groups were low. However, if P levels were high, DOC levels in plasma of a number of women pregnant with a dead fetus were not nearly as high as those in women pregnant with a live fetus with comparably high levels of $P$. This finding could have been interpreted to mean that the fetus does contribute DOC to the maternal compartment, or else it could be interpreted to mean that extraadrenal steroid 21-hydroxylase activity is increased by a hormonal event of pregnancy that is lost or diminished after fetal death. Based on the results of this study, we speculated that estrogen, the levels of which ordinarily fall precipitously after fetal death, may stimulate the extraadrenal 21-hydroxylation of $P$. In the present investigation this hypothesis was tested and evidence was obtained that estrogen, acting directly or indirectly, causes increased DOC formation from plasma $P$.

\section{METHODS}

Experimental design. Two groups of pregnant women were studied. The first group of subjects $(n=35)$ was comprised of normal women pregnant with a live fetus. Blood samples were obtained from these women at $\sim 2$-wk intervals from early in pregnancy until term. The levels of $P$ and DOC in plasma of each of the blood samples were determined. The second group of subjects $(n=47)$ of this study were women pregnant with a dead fetus. Special studies were conducted in five of these women (subjects 1-5) and in one other subject (no. 6) who was pregnant with a live fetus that was known to have abnormalities incompatible with extrauterine life. The infant died immediately after birth and at autopsy was found to have pituitary hypoplasia and no adrenal glands.

Subject 1 was pregnant at term, had severe hypertension, and was in active labor. $30 \mathrm{~min}$ after fetal heart tones were heard, fetal heart tones were not present. Blood was obtained at this time and a number of times thereafter. P and DOC were measured in plasma of each of the blood samples and $17 \beta$-estradiol and estriol were quantified in selected samples.

In Subject 2 at 30-wk gestation, fetal heart tones were present, and blood was obtained for reasons unrelated to this study. 1-2 wk later the fetus died. Approximately $1 \mathrm{wk}$ later, this woman was hospitalized for evaluation and study. Blood samples were collected twice daily for $5 \mathrm{~d}$. At the end of this time $25 \mathrm{mg}$ diethylstilbestrol was given to this woman by mouth four times a day for $12 \mathrm{~d}$. Blood sample collection twice daily was continued. Induction of labor by infusion of oxytocin was attempted several times unsuccessfully. After cessation of estrogen treatment, once-daily collection of blood was continued for $15 \mathrm{~d}$. After this time spontaneous rupture of the membranes occurred, and oxytocin induction of labor at this time was successful. DOC and P in plasma of each of the blood samples, including that which was collected before fetal death, were quantified. In addition $17 \beta$ estradiol and estriol also were measured in selected plasma samples.

Subject 3 was pregnant at 35-36-wk gestation when fetal death occurred for unknown reasons. Approximately 1 wk after fetal demise this woman was hospitalized for evaluation. Blood was collected twice daily for $5 \mathrm{~d}$ before commencing diethylstilbestrol treatment. On day 2 of estrogen treatment labor commenced spontaneously and delivery occurred after $18 \mathrm{~h}$. Steroids in plasma of each of the blood samples were quantified.

Subject 4 was pregnant at 32-34-wk gestation when fetal death occurred. Near the time of fetal death there was sonographic evidence of hydrops fetalis, presumably due to nonimmunologic causes. Approximately 1-2 wk after fetal demise blood was collected from this woman on 2 successive $\mathrm{d}$, and an intravenous infusion of a tracer dose of $\left[{ }^{3} \mathrm{H}\right] \mathrm{P}$ $(\sim 50 \mu \mathrm{Ci})$ plus $\left[{ }^{14} \mathrm{C}\right] \mathrm{DOC}(\sim 0.2 \mu \mathrm{Ci})$ was given. Urine was collected for $48 \mathrm{~h}$. The [ $\rho[]_{B \cup}^{\mathrm{P} . D O C}$ and the production rate $(\mathrm{PR})$ of DOC were computed from the ${ }^{3} \mathrm{H} /{ }^{14} \mathrm{C}$ ratio and the specific activity, respectively, of urinary tetrahydro-DOC as described (14). After $2 \mathrm{~d}$ of diethylstilbestrol treatment (25 $\mathrm{mg}$, four times daily), a second infusion of $\left[{ }^{3} \mathrm{H}\right] \mathrm{P}$ and $\left[{ }^{14} \mathrm{C}\right]$ DOC was given, and urine was collected again for $48 \mathrm{~h}$. The $[\rho]_{\mathrm{BU}}^{\mathrm{P} D \mathrm{DOC}}$ PR-DOC during estrogen treatment were determined. Estrogen treatment was continued for $5 \mathrm{~d}$. During this time oxytocin induction of labor was unsuccessful. $8 \mathrm{~d}$ after discontinuation of estrogen treatment, oxytocin induction of labor was successful. The placenta at delivery, even after several weeks of fetal death was large, viz., $785 \mathrm{~g}$.

Subject 5, who was pregnant at $36 \mathrm{wk}$ when fetal death occurred for unknown reasons, was hospitalized $\sim 1 \mathrm{wk}$ after fetal death. Blood samples were collected intermittently for $5 \mathrm{~d}$ before commencing estrogen treatment, during which time an intravenous infusion of $\left[{ }^{3} \mathrm{H}\right] \mathrm{P}$ and $\left[{ }^{14} \mathrm{C}\right] \mathrm{DOC}$ was given. $2 \mathrm{~d}$ after commencing estrogen treatment $(25 \mathrm{mg}$ diethylstilbestrol, four times daily), a second identical infusion was given. Urine was collected for $48 \mathrm{~h}$ after each tracer infusion. Estrogen treatment was continued for $6 \mathrm{~d}$. Oxytocin induction of labor was successful the day after estrogen treatment was discontinued.

Subject 6 was pregnant at term with a live fetus that was known to have congenital abnormalities incompatible with extrauterine life. By sonographic and radiographic examination the diagnosis of severe hydrocephalus, omphalocele, and thantrophoric dwarfism was made. The metabolic clearance rate (MCR) of DOC was measured in this woman before and during diethylstilbestrol ( $25 \mathrm{mg}$, four times daily) treatment. Before estrogen treatment, $90 \mu \mathrm{Ci}\left[{ }^{3} \mathrm{H}\right] \mathrm{DOC}$ in 0.15 $\mathrm{M} \mathrm{NaCl}$ solution containing $6 \%$ ethanol was infused at a constant rate for $199 \mathrm{~min} .50 \mathrm{ml}$ of blood was collected after 145,170 , and $195 \mathrm{~min}$ of infusion. Urine was collected for $48 \mathrm{~h}$ after beginning the infusion. $48 \mathrm{~h}$ after initiating estrogen treatment the measurement of MCR-DOC was repeated. $\left[{ }^{3} \mathrm{H}\right] \mathrm{DOC}(94 \mu \mathrm{Ci})$ was infused at a constant rate for $202 \mathrm{~min}$. Blood was collected after 140,170, and $200 \mathrm{~min}$ of infusion. Spontaneous labor commenced $20 \mathrm{~h}$ after the completion of the second infusion of radiolabeled tracers. An infant (Apgar 1, 3,300 g) was born that died within 15 min of birth. At autopsy the pituitary was hypoplastic and adrenal glands were not found. The final diagnosis was shortrib polydactyly dwarfism with multiple congenital defects. Before delivery, the mean estriol level in maternal plasma was very low, viz., $2.3 \mathrm{ng} / \mathrm{ml}$. However, the mean plasma level of $17 \beta$-estradiol was $23.8 \mathrm{ng} / \mathrm{ml}$.

Quantification of steroids in plasma. P (15), DOC (7), 
$17 \beta$-estradiol, and estriol (16) were measured by radioimmunoassay procedures previously described in detail.

Steroids. $\left[1,2,6,7-(\mathrm{N})-{ }^{3} \mathrm{H}\right] \mathrm{P}(98 \mathrm{Ci} / \mathrm{mmol})$ and $\left[4-{ }^{14} \mathrm{C}\right] \mathrm{DOC}$ (40 $\mathrm{mCi} / \mathrm{mmol}$ ) (New England Nuclear Corp., Boston, Mass.) were purified as described $(12,14)$. Nonradiolabeled DOC and tetrahydro-DOC were purchased from Steraloids (Wilton, N. H.). 5 $\beta$-Pregnan-3 $\alpha$-ol-20-one-21-acetate was synthesized from $5 \beta$-pregnan-3 $\alpha, 21$-diol-20-one according to the procedure of Henbest et al. (17), and this product was treated with pyridine/acetic anhydride $(1: 1)$ at $37^{\circ} \mathrm{C}$ for 2 $\mathrm{h}$ to obtain tetrahydro-DOC-diacetate.

Determination of MCR, PR-DOC, and ( $\left.[\rho]_{B U}^{P . D O C}\right)$. The MCR-DOC was computed from the steady-state concentration of $\left[{ }^{3} \mathrm{H}\right] \mathrm{DOC}$ in plasma during the continuous infusion of a tracer dose of $\left[{ }^{3} \mathrm{H}\right] \mathrm{DOC}$ in Subject 6. $\left[{ }^{14} \mathrm{C}\right] \mathrm{DOC}(\sim 3,000$ dpm) was added to each plasma sample as an internal standard. The plasma was extracted twice with dichloromethane. An aliquot (5\%) of the extract was assayed for radioactivity and the ${ }^{3} \mathrm{H} /{ }^{14} \mathrm{C}$ ratio of the steroid(s) in the extract was computed. The solvent was evaporated and the residue was purified by thin-layer chromatography (TLC) using the solvent system methylene chloride/diethyl ether $(7: 3, \mathrm{vol} / \mathrm{vol})$. The purified DOC was eluted from the silica gel and treated with a mixture of pyridine and acetic anhydride for $2 \mathrm{~h}$ at $37^{\circ} \mathrm{C}$. The DOC-acetate was chromatographed by TLC using the solvent system ethyl acetate/isooctane (1:1, vol/vol). The DOC-acetate was eluted from the chromatogram, 40 mg nonradiolabeled DOC-acetate was added, and the mixture was crystallized three times. The ${ }^{3} \mathrm{H} /{ }^{14} \mathrm{C}$ ratios in the plasma extract and after each purification step were similar (data not shown). The plasma PR-DOC was computed as the product of the MCR-DOC and the plasma concentration of DOC (Table II).

In Subjects 4 and 5 , the $[\rho]_{\mathrm{BU}}^{\mathrm{P}-\mathrm{DOC}}$ was computed from the relationship between the ${ }^{3} \mathrm{H} /{ }^{14} \mathrm{C}$ ratio of the infused tracers, $\left[{ }^{3} \mathrm{H}\right] \mathrm{P}$ and $\left[{ }^{14} \mathrm{C}\right] \mathrm{DOC}$, and that of tetrahydro-DOC isolated from a 48-h urine collection that was treated with $\beta$-glucuronidase. The procedures used for the purification of urinary tetrahydro-DOC have been described in detail (11). The production rate of DOC was computed from the specific activity of urinary tetrahydro-DOC with respect to carbon14 and the quantity of $\left[{ }^{14} \mathrm{C}\right] \mathrm{DOC}$ infused (14). The specific activity of tetrahydro-DOC was determined after acetylation of an aliquot of the tetrahydro-DOC with $\left[{ }^{3} \mathrm{H}\right]$ acetic anhydride of known specific activity.

The PR-DOC in Subject 6 was computed from the specific activity of $\left[{ }^{3} \mathrm{H}\right]$ tetrahydro-DOC isolated from a $48-\mathrm{h}$ urine collection that was treated with $\beta$-glucuronidase. The $\left[{ }^{3} \mathrm{H}\right]$ tetrahydro-DOC was purified as described (11). The specific activity of the purified $\left[{ }^{3} \mathrm{H}\right]$ tetrahydro-DOC was computed from the ${ }^{3} \mathrm{H} /{ }^{14} \mathrm{C}$ ratio of tetrahydro-DOC-diacetate after acetylation of the $\left[{ }^{3} \mathrm{H}\right]$ tetrahydro-DOC with $\left[{ }^{14} \mathrm{C}\right]$ acetic anhydride of known specific activity (14). The tetrahydroDOC-diacetate was purified by TLC and by recrystallization to constant ${ }^{3} \mathrm{H} /{ }^{14} \mathrm{C}$ ratios.

\section{RESULTS}

Plasma levels of DOC and $P$ in women pregnant with a dead fetus and in women pregnant with a live fetus. The concentrations of DOC in plasma, as a function of the concentrations of $P$ in plasma, in women pregnant with a dead fetus are compared with the concentrations of DOC and P in women pregnant with a live fetus (Fig. 1). When the plasma levels of

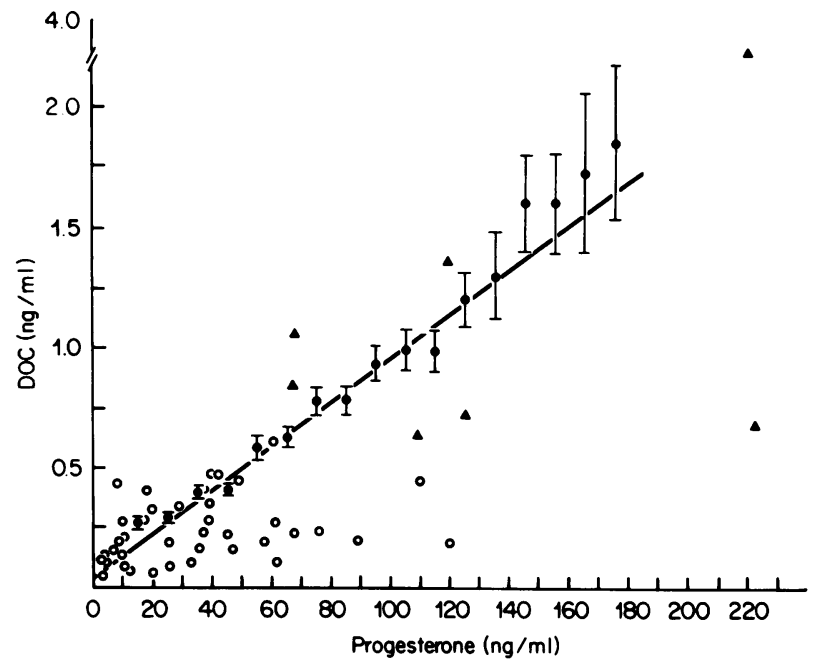

FIGURE 1 The concentrations of DOC in plasma as a function of the concentration of $P$ in plasma (mean \pm SEM) in women pregnant with a live fetus (O) are compared with those in women pregnant with a dead fetus and in whom plasma $17 \beta$-estradiol levels are less than $(O)$ or greater than (А) $6 \mathrm{ng} / \mathrm{ml}$.

$P$ were low $(<50 \mathrm{ng} / \mathrm{ml})$, the plasma levels of DOC in women pregnant with a dead fetus were quite variable but in most instances were similar to those in women pregnant with a live fetus (Fig. 1). On the other hand, when $\mathrm{P}$ levels in plasma were high $(>50$ $\mathrm{ng} / \mathrm{ml}$ ), the levels of DOC in plasma of most women pregnant with a dead fetus were considerably lower than the levels of DOC in plasma of women pregnant with a live fetus. In the case of women pregnant with a dead fetus with high levels of $P$ and low levels of DOC, the concentration of $17 \beta$-estradiol usually was low, i.e., $<6 \mathrm{ng} / \mathrm{ml}$. In five women pregnant with a dead fetus the levels of both $P$ and DOC were high. In four of these five women the plasma levels of $17 \beta$ estradiol were $>6 \mathrm{ng} / \mathrm{ml}$ (Fig. 1).

The plasma levels of $P$ and DOC in a woman soon after fetal death and sequentially thereafter until and after delivery. The levels of DOC and P in the plasma of a near-term pregnant woman (Subject 1) soon (within $30 \mathrm{~min}$ ) after fetal death and every 30 min thereafer until $3 \mathrm{~h}$ after delivery, hourly until 10 $\mathrm{h}$ postpartum, and at 24,36 , and $60 \mathrm{~h}$ after delivery are presented in Fig. 2. The levels of $P$ and those of DOC fluctuated somewhat before delivery, but the concentration of both steroids remained high. After delivery the levels of $\mathbf{P}$ and DOC in plasma declined rapidly. These findings are consistent with the view that DOC in the maternal compartment of some women is derived primarily from the extraadrenal 21hydroxylation of plasma $\mathrm{P}$ and not by transfer to the mother of DOC produced in the fetus. 


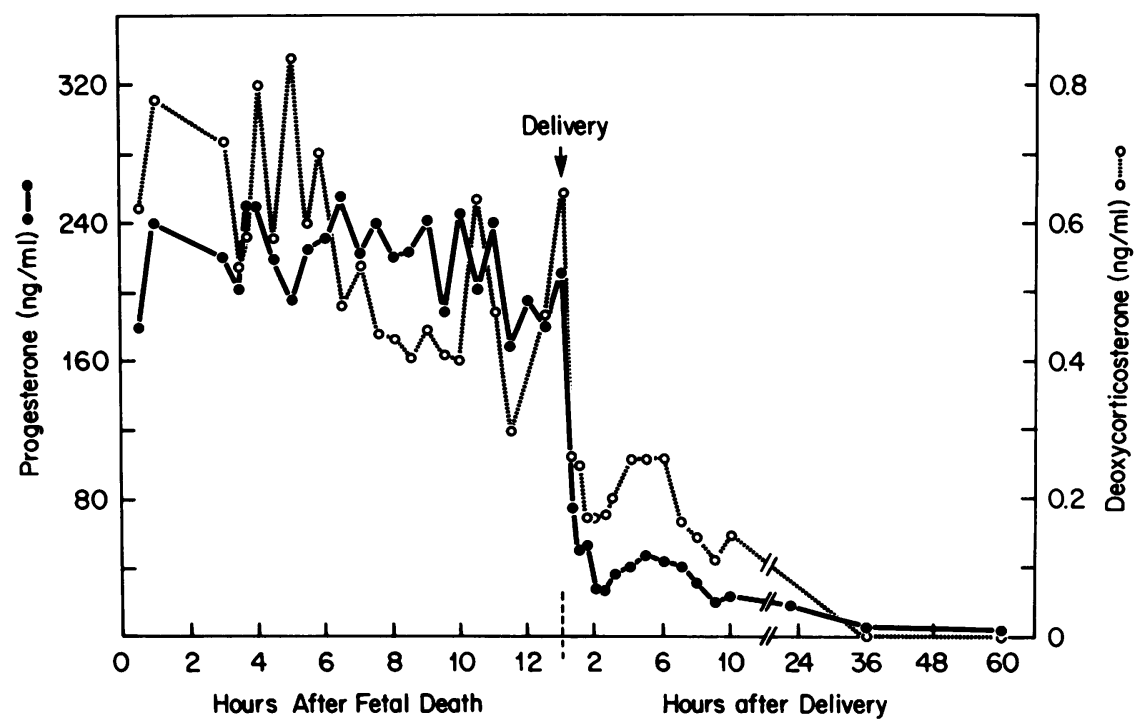

Figure 2 The levels of DOC and $P$ in the plasma of a near-term pregnant woman (Subject 1) within $30 \mathrm{~min}$ after fetal death and at various times thereafter.

The plasma levels of $P$ and DOC in women pregnant with a dead fetus before and during estrogen treatment. The levels of $\mathrm{P}$ and DOC in plasma of Subject 2 at 30 -wk gestation, when her fetus was alive, as well as the levels of these hormones after fetal death before and during estrogen treatment are presented in Fig. 3A. The ratios of the concentrations of DOC to those of $P$ in this subject are presented in Fig. 3B. In this woman the concentration of $17 \beta$-estradiol in plasma before fetal death was $7.8 \mathrm{ng} / \mathrm{ml}$ and $1-2 \mathrm{wk}$ after fetal death it was $4.3 \mathrm{ng} / \mathrm{ml}$. The plasma estriol level was $3.1 \mathrm{ng} / \mathrm{ml}$ before fetal death and was $<0.5$ $\mathrm{ng} / \mathrm{ml}$ after fetal death. Before fetal death the plasma level of DOC $(0.952 \mathrm{ng} / \mathrm{ml})$ and that of $P(78 \mathrm{ng} / \mathrm{ml})$ were similar to those found in women pregnant with a live fetus at comparable stages of pregnancy. After fetal death the levels of DOC, but not those of $P$, declined. However, after the institution of estrogen treatment, the concentration of DOC, but not that of $P$ rose. The level of DOC before estrogen treatment, $0.24 \pm 0.023 \mathrm{ng} / \mathrm{ml}$ (mean $\pm \mathrm{SEM})$, was significantly less than that during estrogen treatment, $0.54 \pm 0.053 \mathrm{ng} /$ $\mathrm{ml}, P<0.001$. Importantly the mean ratio of the plasma concentrations of DOC to those of $P$ during estrogen treatment, $0.010 \pm 0.0007$, was similar to the ratio found before fetal death, 0.012 , and significantly greater $(P<0.001)$ than the mean ratio found after fetal death but before estrogen treatment, $0.003 \pm 0.0004$. After the discontinuation of estrogen treatment the ratio of the concentration of DOC to that of $\mathrm{P}$ remained high. However, by this time placental function had deteriorated to such an extent that $P$ levels had declined appreciably to levels similar to or less than those found during the luteal phase of the ovarian cycle.

Similar studies were conducted in Subjects 3-6. The results of these studies are presented in Figs. 4-7. The plasma $17 \beta$-estradiol level in Subject 3 was low, 5.2 $\mathrm{ng} / \mathrm{ml}$, as was the mean of the estriol levels in plasma of several blood samples, $0.93 \mathrm{ng} / \mathrm{ml}$. Within $12 \mathrm{~h}$ of commencement of estrogen treatment, the concentration of DOC in plasma increased (Fig. 4A). Within 24 $h$ the maximum concentration of DOC as well as a high ratio of the concentration of DOC to $\mathrm{P}$ during estrogen treatment (Fig. 4B) was attained. The plasma concentration of DOC before estrogen treatment, $0.48 \pm 0.026 \mathrm{ng} / \mathrm{ml}$, was significantly less than during estrogen treatment, $1.05 \pm 0.11 \mathrm{ng} / \mathrm{ml}, P<0.001$. Similarly the ratios of the plasma concentration of DOC to that of $P$ before estrogen, $0.0047 \pm 0.0003$ was significantly less than during estrogen treatment, $0.0133 \pm 0.0023, P<0.001$.

The plasma concentration of $17 \beta$-estradiol in Subject 4 was high, viz., $24 \mathrm{ng} / \mathrm{ml}$, whereas the concentration of estriol was low, viz., $3 \mathrm{ng} / \mathrm{ml}$. After instituting estrogen treatment, the levels of DOC, which were high before estrogen treatment, increased to very high, although fluctuating levels (Fig. 5A). Similarly the high ratio of the plasma concentration of DOC to that of $P$ before estrogen treatment was increased even higher during estrogen treatment (Fig. 5B). Indeed, on one occasion during estrogen treatment, a ratio of the concentrations of DOC to $\mathrm{P}$ of 0.1 was found. The mean of the plasma concentrations of DOC before estrogen treatment, $4.11 \pm 0.38 \mathrm{ng} / \mathrm{ml}$, was significantly less than during estrogen treatment, $7.22 \pm 0.85 \mathrm{ng} / \mathrm{ml}, P<0.01$. 

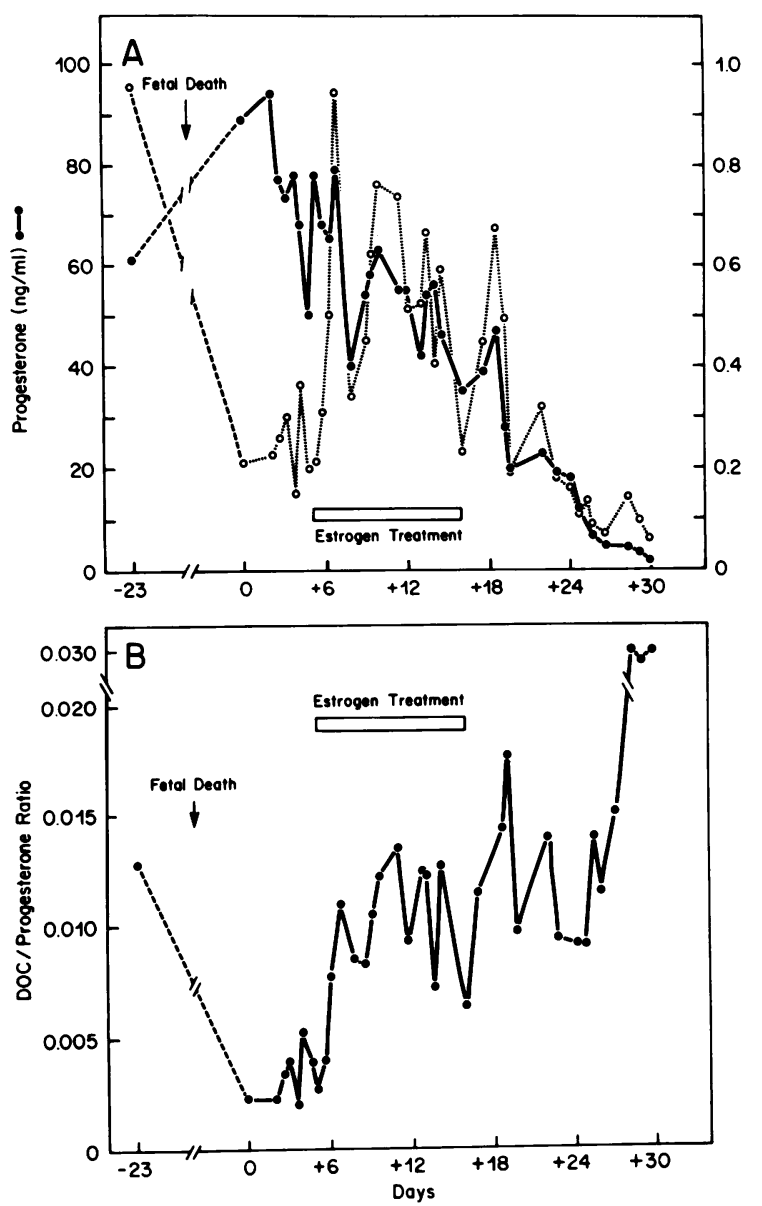

Figure 3 The levels of $P$ and DOC in plasma (panel $A$ ) and the ratios of the concentrations of DOC to those of $P$ (panel $B$ ) in Subject 2 at 30-wk gestation, when her fetus was alive, and after fetal death both before and during estrogen treatment.

The mean of the ratios of the plasma concentrations of DOC to those of $\mathrm{P}$ before estrogen treatment, $0.020 \pm 0.0024$, was significantly less than during estrogen treatment, $0.043 \pm 0.0073, P<0.02$. In this subject the plasma levels of $P$ were quite high, possibly due to the hyperplacentosis that is associated with hydrops fetalis. After discontinuing estrogen treatment the plasma concentration of DOC, as well as the ratio of the concentration of DOC to that of $P$, declined.

In Subject 5 the plasma concentrations of $17 \beta$-estradiol and estriol were low, viz., $<1 \mathrm{ng} / \mathrm{ml}$. After the initiation of estrogen treatment, the levels of DOC did not rise appreciably (Fig. 6A), nor did the ratio of the concentration of DOC to that of P (Fig. 6B). However, placental function had declined appreciably and the mean concentration of plasma $P$ during estrogen treatment, $14.6 \pm 1.5 \mathrm{ng} / \mathrm{ml}$, was significantly less than that before estrogen treatment, $19.1 \pm 1.1 \mathrm{ng} / \mathrm{ml}, P<0.05$. Nonetheless the $[\rho]_{\mathrm{BU}}^{\mathrm{P}-\mathrm{DOC}}$ in this woman, as discussed below, did rise during estrogen treatment.

In Subject 6, pregnant with a deformed but live fetus with adrenal aplasia, the plasma concentration of $17 \beta$ estradiol was high, viz., $24 \mathrm{ng} / \mathrm{ml}$, whereas the plasma concentration of estriol was low, viz., $2.3 \mathrm{ng} / \mathrm{ml}$. During estrogen treatment the levels of DOC (Fig. 7A) as well as the ratios of the plasma concentrations of DOC to those of $\mathrm{P}$ (Fig. 7B) increased appreciably. The mean concentration of DOC before estrogen treatment, $1.63 \pm 0.10 \mathrm{ng} / \mathrm{ml}$, was significantly less than that during estrogen treatment, $2.44 \pm 0.14 \mathrm{ng} / \mathrm{ml}, P<0.001$. The mean of the ratios of the plasma concentrations of DOC to those of $\mathrm{P}$ before estrogen treatment, $0.015 \pm 0.0007$, was significantly less than during estrogen treatment, $0.0254 \pm 0.0023, P<0.01$.

The $[\rho]_{B U}^{P-D O C}$ and PR-DOC before and during estrogen treatment in women pregnant with a dead fetus. After
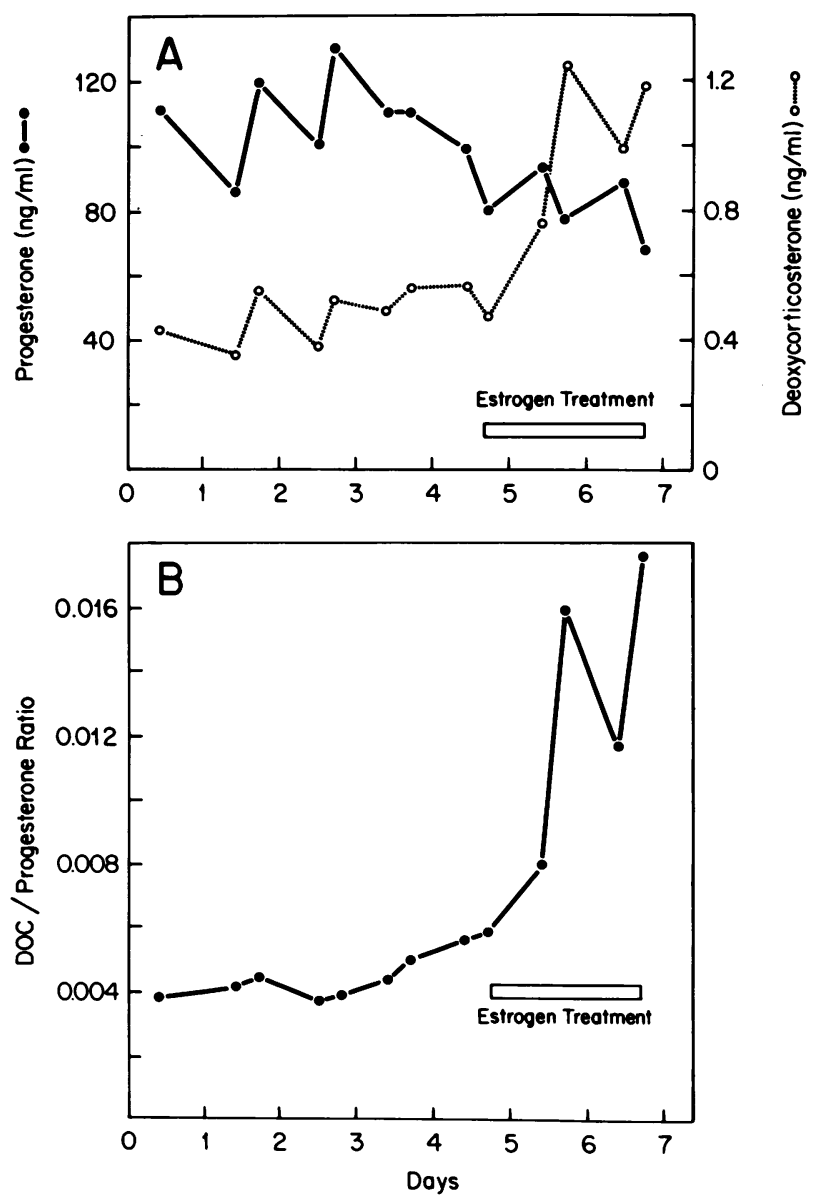

Figure 4 The levels of $P$ and DOC in plasma (panel $A$ ) and the ratio of the concentrations of DOC to those of $P$ (panel $B$ ) in Subject 3 before and during estrogen treatment. 

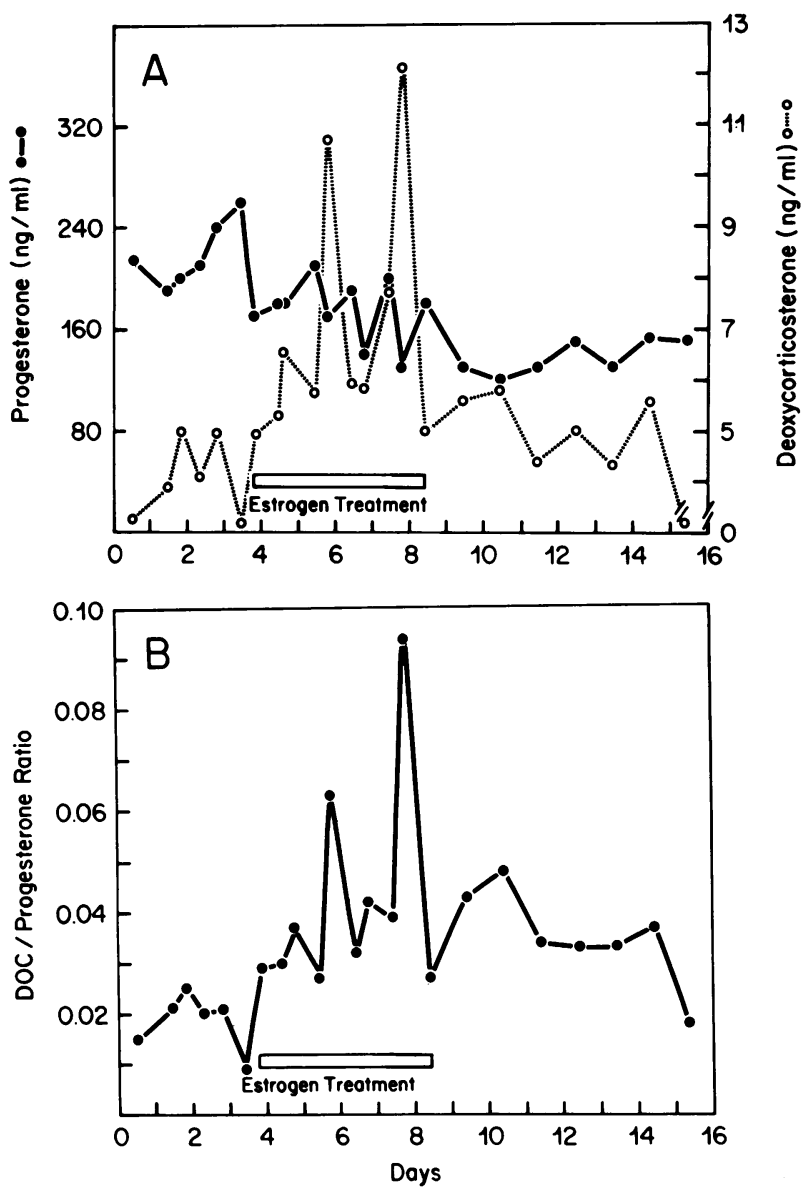

Figure 5 The levels of $P$ and DOC in plasma (panel $A$ ) and the ratio of the concentrations of DOC to those of $P$ (panel $B$ ) in Subject 4 before and during estrogen treatment.

purification to radiochemical homogeneity of radiolabeled tetrahydro-DOC isolated from the urine of Subjects 4 and 5 (who were given an intravenous infusion of $\left[{ }^{3} \mathrm{H}\right] \mathrm{P}$ and $\left.\left[{ }^{14} \mathrm{C}\right] \mathrm{DOC}\right)$, the $[\rho]_{\mathrm{BU}}^{\mathrm{p} \text { :DOC }}$ in each subject was computed. The $\left[\rho{ }_{\mathbb{B} U}^{p \cdot D O C}\right.$ in Subject 4 was 0.011 before estrogen treatment and was 0.024 during estrogen treatment (Table I). Similarly, the $[\rho]_{B U}^{p \cdot D O C}$ in Subject 5 rose from 0.005 before to 0.013 during estrogen treatment (Table I).

The PR-DOC (computed from the specific activity of urinary tetrahydro-DOC) in Subject 4 was $7.7 \mathrm{mg} /$ $24 \mathrm{~h}$ before and $12.2 \mathrm{mg} / 24 \mathrm{~h}$ during estrogen treatment. In Subject 5 the PR-DOC before and during estrogen treatment were 0.75 and $0.63 \mathrm{mg} / 24 \mathrm{~h}$, respectively. However, in Subject 5 plasma $P$ levels were low and falling. Thus despite an increase in $[\rho]_{\mathrm{BU}}^{\mathrm{P}-\mathrm{DOC}}$ during estrogen treatment, PR-DOC did not rise. The MCRDOC was not measured in Subjects 4 and 5. However if we assume that MCR-DOC in these women was similar to that in Subject 6 of this study and to those found by
Nolten et al. (18), viz., $~ 1,600$ liter/d, we can estimate the plasma PR-DOC. Doing so we computed that the estimated value for plasma PR-DOC was similar to that measured by the isotope dilution technique (Table I).

The MCR-DOC and plasma PR-DOC in a woman pregnant with a severely deformed fetus with adrenal aplasia before and during estrogen treatment. After purification to radiochemical homogeneity of DOC in plasma from blood samples obtained during the infusion of $\left[{ }^{3} \mathrm{H}\right] \mathrm{DOC}$ to Subject 6 , the MCR-DOC was computed. The MCR-DOC in Subject 6 was 1,596 liter/24 $\mathrm{h}$ before estrogen treatment and was 1,583 liter/ $24 \mathrm{~h}$ during estrogen treatment (Table II). The plasma PR-DOC before and during estrogen treatment were 2.75 and $4.31 \mathrm{mg} / 24 \mathrm{~h}$, respectively, in this woman (Table II).
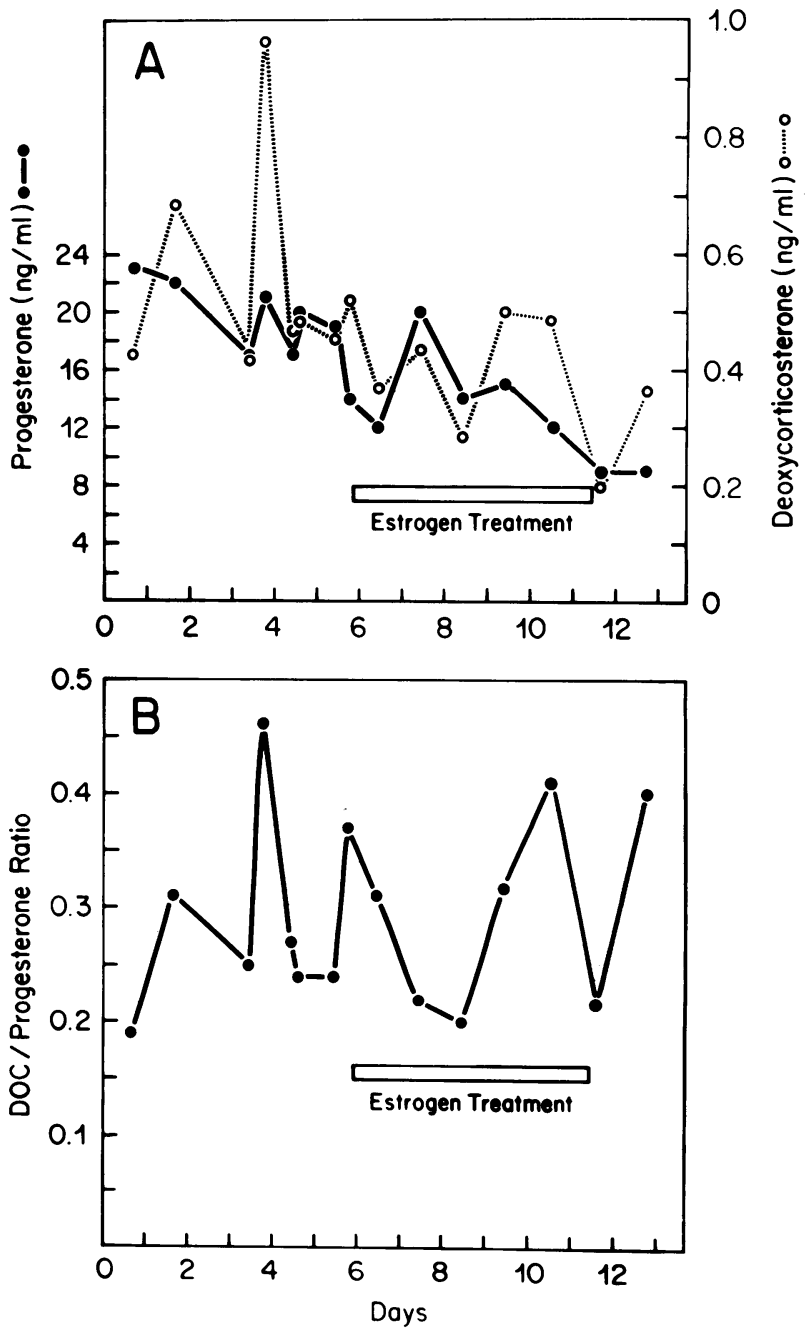

Figure 6 The levels of $P$ and DOC in plasma (panel $A$ ) and the ratio of the concentrations of DOC to those of $P$ (panel B) in Subject 5 before and during estrogen treatment. 

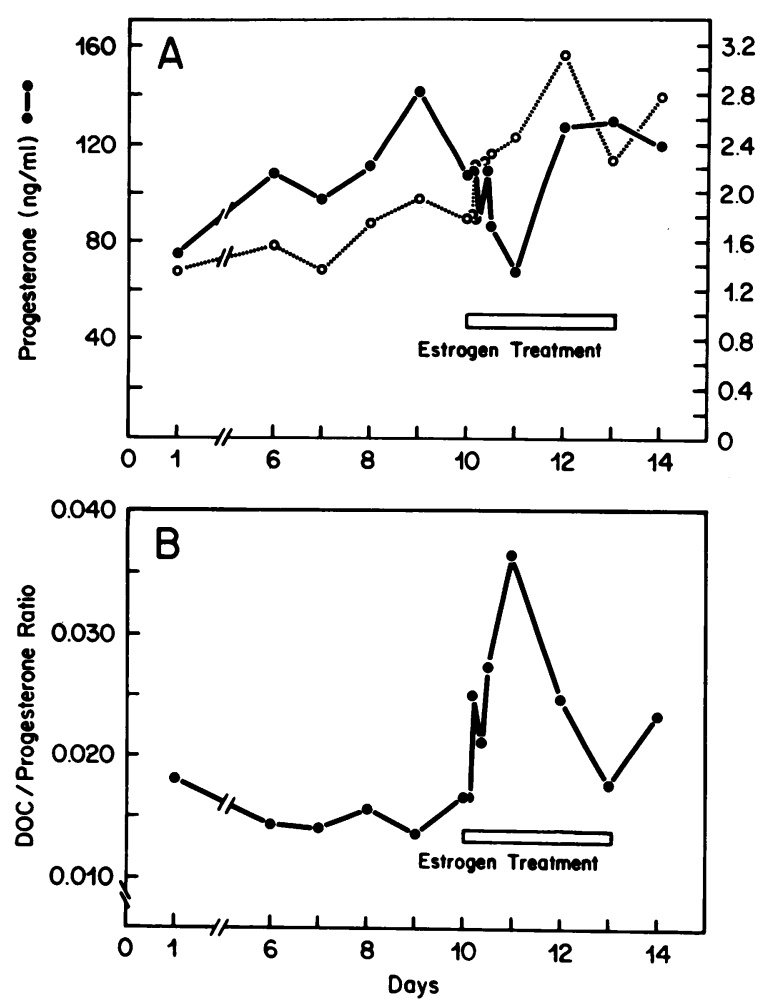

Figure 7 The levels of $P$ and DOC in plasma (panel $A$ ) and the ratio of the concentrations of DOC to those of $P$ (panel B) in Subject 6 before and during estrogen treatment.

\section{DISCUSSION}

This investigation was designed originally to ascertain whether significant quantities of DOC were trans- ferred from the fetal to the maternal compartment. We were of the view that this was not the case. This conclusion was based primarily upon the finding that much of the DOC in pregnant women can be accounted for by the extraadrenal production of DOC from plasma $P$ (11). Thus, we were surprised to find that when plasma $P$ levels were high the plasma levels of DOC were lower than expected in some women pregnant with a dead fetus. However, it also was observed that when $P$ levels were low the plasma concentrations of DOC were similar among most pregnant women irrespective of whether the fetus was alive or dead. In five women pregnant with a dead fetus plasma $P$ levels were high and DOC levels also were high. In four of these five women the plasma $17 \beta$-estradiol levels also were high. These findings were suggestive that the rate of formation of DOC from circulating $P$ may be regulated by estrogen, which is produced in large amounts in pregnancies in which the fetus is alive.

Estriol is synthesized in the human placenta from $16 \alpha-\mathrm{OH}$-dehydroisoandrosterone sulfate derived primarily from the fetus $(19,20)$ and $17 \beta$-estradiol is synthesized in the placenta from dehydroisoandrosterone sulfate and other circulating $\mathrm{C}_{19}$-steroids derived from both fetal and maternal plasma $(19,21-22)$. $P$ is synthesized in the placenta almost exclusively from maternal plasma low-density lipoprotein-cholesterol (24). Therefore after fetal death the rate of estrogen synthesis, particularly that of estriol, falls precipitously whereas $\mathbf{P}$ synthesis persists until placental function deteriorates. If estrogen stimulates extraadrenal steroid 21-hydroxylase activity, it could be envisioned that a decline in steroid 21-hydroxylase activity after fetal death would be sufficient to cause a reduction in

TABLE I

Transfer Constant of Conversion of Plasma Progesterone to DOC ([o $]_{\mathrm{BU}}^{\mathrm{P}-\mathrm{DOC})}$ ) and the Production Rate of DOC before and during Estrogen Treatment of Women Pregnant Near Term with a Dead Fetus

\begin{tabular}{|c|c|c|c|}
\hline & Cotboc & PR-DOC• & $\begin{array}{l}\text { Plasma PR- } \\
\text { DOCt }\end{array}$ \\
\hline & & $m g / 24 h$ & $m g / 24 h$ \\
\hline \multicolumn{4}{|l|}{ Subject 4} \\
\hline $\begin{array}{l}\text { Before estrogen treatment } \\
\text { Subject } 4\end{array}$ & 0.011 & 7.7 & 7.2 \\
\hline $\begin{array}{l}\text { During estrogen treatment } \\
\text { Subject } 5\end{array}$ & 0.024 & 12.2 & 12.7 \\
\hline $\begin{array}{l}\text { Before estrogen treatment } \\
\text { Subject } 5\end{array}$ & 0.005 & 0.75 & 0.88 \\
\hline During estrogen treatment & 0.013 & 0.63 & 0.68 \\
\hline
\end{tabular}

- Computed from the specific activity of urinary tetrahydro-DOC

$\downarrow$ Computed from plasma concentration of DOC (average of plasma DOC concentration in four blood samples obtained during $2 \mathrm{~d}$ of urine collection) assuming an MCR-DOC $=1,600 / 24 \mathrm{~h}$. 
TABLE II

Metabolic Clearance Rate and Plasma Production Rate of DOC before and during Estrogen Treatment of a Woman Pregnant Near Term

\begin{tabular}{|c|c|c|c|c|c|c|}
\hline \multirow[b]{2}{*}{ Treatment } & \multicolumn{3}{|c|}{$\left[{ }^{14} \mathrm{C}\right] \mathrm{DOC} /$ liter plasma } & \multirow[b]{2}{*}{ MCR-DOC• } & \multirow{2}{*}{$\begin{array}{c}\text { Plasma } \\
\text { concentration } t \\
\text { DOC }\end{array}$} & \multirow[b]{2}{*}{$\begin{array}{l}\text { Plasma } \\
\text { PR-DOC }\end{array}$} \\
\hline & $\begin{array}{c}\text { Blood sample } \\
\text { No. } 1\end{array}$ & $\begin{array}{c}\text { Blood sample } \\
\text { No. } 2\end{array}$ & $\begin{array}{c}\text { Blood sample } \\
\text { No. } 3\end{array}$ & & & \\
\hline & & $d p m \times 10^{-3}$ & & liters plasma $/ 24 \mathrm{~h}$ & $n g / m l$ & $m g / 24 h$ \\
\hline \multicolumn{7}{|l|}{ Subject 6} \\
\hline Before estrogen treatment & 891 & 876 & 897 & 1,596 & 1.72 & 2.75 \\
\hline \multicolumn{7}{|l|}{ Subject 6} \\
\hline During estrogen treatment & 923 & 807 & 932 & 1,583 & 2.72 & 4.31 \\
\hline
\end{tabular}

- MCR computed from concentration of $\left[{ }^{3} \mathrm{H}\right] \mathrm{DOC}$ in plasma of blood sample No. 3 .

$\$$ Mean plasma DOC concentration in blood samples obtained on four occasions, viz., the day before, the day of, and each of $2 \mathrm{~d}$ after infusion of $\left[{ }^{3} \mathrm{H}\right] \mathrm{DOC}$.

the fractional conversion of plasma $P$ to DOC. This possibility seemed reasonable in view of the similarity between the concentration of $\mathrm{P}$ in plasma of women late in pregnancy and the concentration of $\mathrm{P}$ that is known to saturate the 21-hydroxylase enzyme in human kidney tissue microsomes in vitro (12). If in the latter part of pregnancy extraadrenal steroid 21-hydroxylase enzyme were saturated by $\mathrm{P}$, a decline in enzyme activity would eventuate in a decrease in the fractional conversion of plasma $P$ to DOC. On the other hand, if $\mathrm{P}$ levels do become saturating for extraadrenal steroid 21-hydroxylase late in pregnancy, an estrogen-induced increase in enzyme activity in women pregnant with a live fetus could provide a mechanism for maintaining the fractional conversion of plasma $\mathrm{P}$ to DOC reasonably constant despite rising levels of $\mathrm{P}$ in plasma.

We sought to evaluate this possibility in a study of women pregnant, near term, with a dead fetus. Such subjects were considered to be ideal naturally occurring models for this study for the following reasons. (a) In some such women the plasma levels of $\mathrm{P}$ remain high whereas those of estrogen, particularly estriol, decline precipitously after fetal death. (b) In such women, DOC cannot arise from the fetus. (c) Theoretically estrogen treatment of such women could be therapeutically beneficial because similar treatment of animals brings about an increase in oxytocin receptor concentration in myometrium $(25,26)$. Commonly, women pregnant with a dead fetus are refractory to the induction of labor with oxytocin as were the women of the present study. Moreover, estrogen treatment of pregnant women, even those in whom the fetus is dead, does not produce nausea (27), and in a 25-yr follow-up study of women who ingested diethylstilbestrol during pregnancy, there was no evidence of ill effects (28).

Several studies were conducted. First we evaluated, sequentially, the levels of $\mathrm{P}$ and DOC in plasma of a woman commencing within $30 \mathrm{~min}$ after fetal death. The levels of the two hormones remained reasonably constant until after delivery of the placenta. Thereafter the levels of the two hormones declined precipitously. These findings are suggestive that in some pregnancies significant quantities of DOC are not transferred from fetus to mother.

In a second study we sought to ascertain if the administration of estrogen to women pregnant with a fetus that had been dead from some time would give rise to an increase in the levels of DOC in plasma, presumably as the consequence of stimulation of extraadrenal steroid 21-hydroxylase activity. We found that within $12 \mathrm{~h}$ after the initiation of estrogen treatment of four women pregnant with a dead fetus, DOC levels had risen appreciably in three of the four. Perhaps more importantly, the ratio of the concentration of DOC to that of $P$ (which was depressed markedly after fetal death) had risen strikingly in these three women. Indeed in one of these women the ratio of the concentrations of DOC to those of P during estrogen treatment was similar to that found when her fetus was alive. The ratio of the plasma concentration of DOC to that of $\mathrm{P}$ (corrected for difference in the metabolic clearance rates of the two steroids) should be similar to the transfer constant of conversion of plasma $P$ to DOC provided that the proportion of DOC in plasma that arose by secretion from the maternal adrenal or by transfer from the fetus is small compared to that which is formed from plasma $P$ when plasma $P$ levels are high. In one subject (no. 5), DOC levels did not rise appreciably during estrogen treatment. However, the plasma levels of $P$ in this woman were very low and were falling during estrogen treatment. Even in this woman the $[\rho]_{B U}^{p-D O C}$ increased 2.6-fold during estrogen treatment.

After cessation of estrogen treatment of Subject 2, 
the ratio of the concentration of DOC in plasma to that of $\mathrm{P}$ remained high. However, by this time the levels of $P$ in her plasma had fallen to levels similar to those found in the luteal phase of the ovarian cycle. We have shown previously that the $\left[\rho{ }_{B U}^{p-D O C}\right.$ in a given woman is similar in the follicular and luteal phase of her cycle (29). Thus despite the discontinuation of estrogen treatment it is likely that the level of steroid 21-hydroxylase activity was sufficient to maintain the transfer constant of conversion of plasma $P$ to DOC sufficient for these lower levels of $P$.

To test directly whether the increase in the plasma concentration of DOC during estrogen treatment was due to increased 21-hydroxylation of plasma $P$, the $[\rho]_{B \cup}^{\text {P.DOC }}$ and PR-DOC were determined before and during estrogen treatment in two subjects pregnant with a dead fetus. The $[\rho]_{\mathrm{BU}}^{\mathrm{p} \text {-DOC }}$ increased during estrogen treatment in both subjects. In Subject 4 the PR-DOC before estrogen treatment was $7.7 \mathrm{mg} / 24 \mathrm{~h}$ whereas during estrogen treatment it was $12.2 \mathrm{mg} / 24 \mathrm{~h}$. The PR-DOC before and during estrogen treatment of Subject 5 were similar. However as noted before the plasma $P$ levels in this woman during estrogen treatment were low and falling. Thus the increase in $[\rho]_{B U}^{\text {P.DOC }}$ may have allowed for maintenance of the pretreatment PR-DOC despite falling levels of $P$.

These findings are suggestive that the rise in plasma concentration of DOC, as well as the increase in the PR-DOC, during estrogen treatment was due to increased conversion of circulating progesterone to DOC and was not due to increased maternal adrenal secretion of DOC. In addition it was found that in one woman pregnant with a live but deformed fetus with adrenal aplasia, the MCR-DOC did not decrease during estrogen treatment and the values for MCR-DOC in this woman were similar to those found previously in nonpregnant women $(11,18)$. In this subject the plasma PR-DOC was $2.75 \mathrm{mg} / 24 \mathrm{~h}$ before estrogen treatment and was $4.31 \mathrm{mg} / 24 \mathrm{~h}$ during estrogen treatment. These several findings are supportive of the conclusion that increased levels of cortisol binding globulin did not account for the increased levels of DOC observed during estrogen treatment of women pregnant with a dead fetus.

Based on the findings of the present and previous $(7,11)$ investigations we conclude that the DOC present in blood of most near-term pregnant women is derived primarily from the extraadrenal 21-hydroxylation of plasma $P$. The extraadrenal 21-hydroxylation of plasma $P$ may take place, in part, in kidney $(12,13)$, a tissue site of DOC action. Moreover, steroid 21-hydroxylase activity in extraadrenal tissue was stimulated by estrogen. From the results of this study we cannot deduce whether estrogen acts directly or indirectly, e.g., through an alteration in the rate of formation of a substance (possibly a pituitary hormone) that stimulates extraadrenal steroid 21-hydroxylase activity. The kidney, however is believed to be a tissue of estrogen responsiveness $(30,31)$. In any event it seems likely that estrogen, acting directly or indirectly, stimulates extraadrenal steroid 21-hydroxylase activity in a manner such that the transfer constant of conversion of plasma progesterone to DOC remains reasonably constant as pregnancy advances and plasma levels of $P$ rise. In this manner the production rate of DOC in most women pregnant with a live fetus remains proportional to the plasma concentration of $\mathbf{P}$.

\section{ACKNOWLEDGMENTS}

We thank Messrs. Frank Hereford, Jesse Smith, and Shelton Ragland for expert technical assistance and Ms. Becky McKinney-Reese and Vicki Rankin for valuable editorial assistance.

This investigation was supported, in part, by U. S. Public Health Service grants no. 5-P50-HD11149, 5-R01-HD14513, and 5-P01-AG00306. Dr. Casey is a postdoctoral trainee supported, in part, by U.S. Public Health Service training grant no. 1-T32-HD07190.

\section{REFERENCES}

1. Brown, R. D., C. A. Strott, and G. W. Liddle. 1972. Plasma deoxycorticosterone in normal and abnormal human pregnancy. J. Clin. Endocrinol. Metab. 35: 736742.

2. Weir, R. J., A. Goig, R. Fraser, J. J. Morton, J. Parboosingh, J. I. S. Robertson, and A. Wilson. 1976. Studies of the renin-angiotensin aldosterone system, cortisol, DOC, and ADH in normal and hypertensive pregnancy. In Hypertension in Pregnancy M. D. Lindheimer, A. I. Katz, and F. P. Zuspan, editors. John Wiley and Sons, New York. 251-261.

3. Ehrlich, E. N., W. E. Nolten, S. Oparil, and M. D. Lindheimer. 1976. Mineralocorticoids in normal pregnancy. In Hypertension in Pregnancy M. D. Lindheimer, A. I. Katz, and F. P. Zuspan, editors. John Wiley and Sons, New York. 189-201.

4. Nolten, W. E., M. D. Lindheimer, S. Oparil, and E. N. Ehrlich. 1978. Desoxycorticosterone in normal pregnancy. I. Sequential studies of the secretory patterns of desoxycorticosterone, aldosterone, and cortisol. Am. J. Obstet. Gynecol. 132: 414-420.

5. Sippell, W. G., H. Becker, H. T. Versmold, F. Bidlingmaier, and D. Knorr. 1978. Longitudinal studies of plasma aldosterone, corticosterone, deoxycorticosterone, progesterone, 17-hydroxy progesterone, cortisol, and cortisone determined simultaneously in mother and child at birth and during the early neonatal period. I. Spontaneous delivery. J. Clin. Endocrinol. Metab. 46: 971985.

6. Nolten, W. E., M. D. Lindheimer, S. Oparil, P. A. Rueckert, and E. N. Ehrlich. 1979. Desoxycorticosterone in normal pregnancy. II. Cortisol-dependent fluctuations in free plasma desoxycorticosterone. Am. J. Obstet. Gynecol. 133: 644-648.

7. Parker, C. R., Jr., R. B. Everett, J. G. Quirk, P. J. Whalley, N. F. Gant, and P. C. MacDonald. 1980. Hormone production in pregnancy in the primigravida. II. Plasma 
concentrations of deoxycorticosterone throughout pregnancy in normal women and in women who developed pregnancy-induced hypertension. Am. J. Obstet. Gynecol. 138: 626-631.

8. Nolten, W. E., L. H. Holt, and P. A. Rueckert. 1981. Desoxycorticosterone in normal pregnancy. III. Evidence of a fetal source of desoxycorticosterone. Am. J. Obstet. Gynecol. 139: 477-482.

9. Schweitzer, M., C. Branchaud, and C. J. P. Giroud. 1969. Maternal and umbilical cord plasma concentrations of steroids of the pregn-4-ene C-21-yl sulfate series at term. Steroids. 14: 519-532.

10. Branchaud, C., M. Schweitzer, and C. J. P. Giroud. 1969. Characterization of the $21-y l$ sulfates of $11 \beta, 17 \alpha, 21-$ trihydroxypregn-4-ene-3, 20-dione; 17 $\alpha, 21$-hydroxypregn-4-ene-3, 11, 20-trione; $11 \beta, 21$-dihydroxypregn-4ene-3, 20-dione; 21-hydroxypregn-4-ene-3, 11, 20-trione and 21-hydroxypregn-4-ene-3, 20-dione in human cord plasma. Steroids. 14: 179-190.

11. Winkel, C. A., L. Milewich, C. R. Parker, Jr., N. F. Gant, E. R. Simpson, and P. C. MacDonald. 1980. Conversion of plasma progesterone to deoxycorticosterone in men, nonpregnant and pregnant women, and adrenalectomized subjects: evidence for steroid 21-hydroxylase activity in nonadrenal tissues. J. Clin. Invest. 66: 803-812.

12. Winkel, C. A., E. R. Simpson, L. Milewich, and P. C. MacDonald. 1980. Desoxycorticosterone (DOC) biosynthesis in human kidney: potential for the formation of a potent mineralocorticosteroid in its site of action. Proc. Natl. Acad. Sci. U. S. A. 77: 7069-7073.

13. Winkel, C. A., M. L. Casey, E. R. Simpson, and P. C. MacDonald. 1981. Deoxycorticosterone (DOC) biosynthesis from progesterone in kidney tissue of the human fetus. J. Clin. Endocrinol. Metab. 53: 10-15.

14. Siiteri, P. K. 1963. The isolation of urinary estrogens and determination of their specific activities following the administration of radioactive precursors to humans. Steroids. 2: 687-712.

15. Milewich, L., C. Gomez-Sanchez, J. D. Madden, and P. C. MacDonald. 1975. Isolation and characterization of $5 \alpha$-pregnan-3,20-dione and progesterone in peripheral blood of pregnant women. Measurement throughout pregnancy. Gynecol. Invest., 6: 291-306.

16. Wright, K., D. C. Collins, and J. R. K. Preedy. 1973. Comparative specificity of antisera raised against estrone, estradiol-17 $\beta$, and estriol using 6-0-carboxymethyloxime bovine serum albumin derivatives. Steroids. 21: 755-769.

17. Henbest, H. B., D. N., Jones, and G. P. Slater. 1961. Reactions of ketones with oxidising agents. Part I. Catalysis of the ketone-lead tetra-acetate reaction with boron trifluoride. J. Chem. Soc. (Lond.). 4472-4478.
18. Nolten, W., P. Vecsi, M. Köhler, I. Purjesz, and H. P. Wolff. 1968. Untersuchungen über sekretion und stoffwechsel von deoxycorticosteron an gesunden und kranken. Verh. Dtsch. Ges. Inn. Med. 74: 1218-1221.

19. Siiteri, P. K., and P. C. MacDonald. 1966. Placental estrogen biosynthesis during human pregnancy. J. Clin. Endocrinol. Metab. 26: 751-761.

20. Bolte, E., N. Wiqvist, and E. Diczfalusy. 1966. Metabolism of dehydroepiandrosterone and dehydroepiandrosterone sulfate by the human foetus at midpregnancy. Acta Endocrinol. 52: 583-587.

21. Siiteri, P. K., and P. C. MacDonald. 1963. The utilization of circulating dehydroisoandrosterone sulfate for estrogen synthesis during human pregnancy. Steroids. 2: 713730.

22. MacDonald, P. C., and P. K. Siiteri. 1965. Origin of estrogen in women pregnant with an anencephalic fetus. J. Clin. Invest. 44: 465-474.

23. Diczfalusy, E., and S. Mancuso. 1969. Foetus and Placenta. Blackwell Scientific. Oxford, England. 191.

24. Winkel, C. A., J. M. Synder, P. C. MacDonald, and E. R. Simpson. 1980. Regulation of cholesterol and progesterone synthesis in human placental cells in culture by serum lipoproteins. Endocrinology. 106: 1054-1060.

25. Soloff, M. S. 1975. Uterine receptor for oxytocin: effects of estrogen. Biochem. Biophys. Res. Commun. 65: 205212.

26. Nissenson, R., G. Flouret, and O. Hechter. 1978. Opposing effects of estradiol and progesterone on oxytocin receptors in rabbit uterus. Proc. Natl. Acad. Sci., U. S. A. 75: 2044-2048.

27. White, P., and H. Hunt. 1943. Pregnancy complicating diabetes. Endocrinology. 3: 500-511.

28. Bibbo, M., W. M. Haenszel, G. L. Wied, M. Hubby, and A. L. Herbst. 1978. A twenty-five-year follow-up study of women exposed to diethylstilbesterol during pregnancy. N. Engl. J. Med. 298: 763-767.

29. Winkel, C. A., C. R. Parker, E. R. Simpson, and P. C. MacDonald. 1980. Production rate of deoxycorticosterone in women during the follicular and luteal phases of the ovarian cycle: the role of extra-adrenal 21-hydroxylation of circulating progesterone in deoxycorticosterone production. J. Clin. Endocrinol. Metab. 51: 13541358.

30. Ghraf, R., E. R. Lax, and H. Schriefers. 1977. Regulation of $3 \alpha$-hydroxy-steroid dehydrogenase activities in rat kidney cytosol. Dependence of estrogenic induction on the endocrine status. Hoppe-Seyler's Z. Physiol. Chem. 358: 699-702.

31. King, R. J. B., and W. I. P. Mainwaring. 1974. Kidney in steroid-cell interactions. University Park Press, Baltimore, Md. 247. 